\title{
LOS PROBLEMAS NO RESUELTOS DE LA DEMOCRACIA Y EL FORTALECIMIENTO DE LA PROTESTA Y LOS MOVIMIENTOS SOCIALES EN EL SIGLO XXI.
}

\author{
THE UNSOLVED PROBLEMS OF DEMOCRACY AND THE STRENGTHENING OF \\ PROTEST AND SOCIAL MOVEMENTS IN THE 21ST CENTURY.
}

\section{Diana Carolina Valencia Tello}

Doctora en Derecho Profesora de la Universidad del Rosario - Colombia

\begin{abstract}
Resumo
Os velhos problemas da democracia representativa continuam sendo mais relevantes do que no passado, porque em um mundo de bilhões de pessoas, os vários interesses, valores e perspectivas de vida colidem sem grande consenso para se encontrar formas de diálogo e acordo para o futuro compartilhado. Os protestos gerados na última década devem ser levados a sério pelos Estados, corporações e organizações internacionais, que devem procurar melhorar os canais de comunicação com a sociedade, fazendo as mudanças e ajustes necessários, para promover a participação e a transparência das decisões públicas que afetam a todos, pois a indignação e a raiva compartilhada dos cidadãos causam protestos maciços que deslegitimam o sistema como um todo. Assim, este artigo procura analisar as deficiências da democracia representativa no mundo digital e, em seguida, explicar o surgimento de fortes protestos e movimentos sociais na última década, destacando como a violência excessiva do poder público afeta os direitos humanos dos cidadãos e quebra as possibilidades de diálogo e consenso nos Estados democráticos de direito. Talvez estejamos em um momento crucial na história da humanidade que exige todo o cuidado para se evitar cair em velhos autoritarismos. Este artigo é para reflexão, mediante a análise de fontes secundárias.
\end{abstract}

Palavras-chave: comunicação. Democracia representativa. Movimentos sociais. Protestos. Redes sociais 


\title{
Resumen
}

Los viejos problemas de la democracia representativa siguen más vigentes que en el pasado, pues en un mundo de billones de personas; los diversos intereses, valores y perspectivas de vida chocan sin mayores consensos para encontrar caminos de dialogo y de acuerdo para futuros compartidos. Las protestas generadas en la última década, deben ser tomadas en serio por los Estados, las corporaciones y las organizaciones internacionales, quienes deben procurar mejorar los canales de comunicación con la sociedad, realizando los cambios y ajustes necesarios, para promover la participación y la transparencia en las decisiones públicas que afectan a todos, antes que la indignación y la rabia compartida de los ciudadanos cause protestas masivas que deslegitimen al sistema en conjunto, afectando seriamente la gobernabilidad en nuestras sociedades. Así, el presente artículo busca analizar las deficiencias de la democracia representativa en el mundo digital, para luego explicar el surgimiento de fuertes protestas y movimientos sociales en la última década; resaltando cómo la violencia excesiva por parte de la fuerza pública, afecta los derechos humanos de los ciudadanos y quiebra las posibilidades de dialogo y consenso en Estados democráticos de derecho. Talvez estamos en un momento crucial en la historia de la humanidad que requiere de todo nuestro cuidado para evitar caer en viejos autoritarismos. El presente artículo es de reflexión, mediante el análisis de fuentes secundarias.

Palabras llave: Comunicación. Democracia Representativa. Movimientos Sociales. Protestas. Redes Sociales

\begin{abstract}
Old problems of representative democracy are more relevant than in the past, because in a world of billions of people; the various interests, values and life prospects collide without major consensus to find ways of dialogue and agreement for shared future. Protests generated in the last decade, should be taken seriously by states, corporations and international organizations, who should seek to improve channels of communication with society, making the necessary changes and adjustments, to promote participation and transparency in public decisions that affect everyone, before the outrage and shared anger of citizens causes massive protests that delegitimize the system as a whole. Thus, this article seeks to analyze the deficiencies of representative democracy in the digital world, and then explain the emergence of strong protests and social movements in the last decade. highlighting how excessive violence by the public force affects the human rights of citizens and breaks the possibilities for dialogue and consensus in democratic states of law. Perhaps we are at a crucial moment in the history of humanity that requires all our care to avoid falling into old authoritarianisms. This article is for reflection, through the analysis of secondary sources.
\end{abstract}

Keywords: Communication. Representative Democracy. Social movements. Protests. Social networks 


\section{CONSIDERACIONES INICIALES}

En Colombia, el 4 de noviembre de 2019 fue convocado por redes sociales un Paro Nacional para el 21 de noviembre, con la finalidad de protestar contra diversas políticas económicas, sociales y ambientales, así como por el incumplimiento del Acuerdo de Paz, el homicidio de lideres sociales, la corrupción y la desigualdad en un país profundamente fragmentado por décadas de conflicto armado.

Fue la primera vez que un Paro Nacional era convocado con tanta anticipación por redes sociales. Las opiniones a favor y en contra, así como las manifestaciones de indignación, miedo y esperanza fueron parte del preludio a la movilización ciudadana del 21 de noviembre, mostrando los profundos desacuerdos entre diferentes sectores y grupos sociales. Por ello, el $21 \mathrm{~N}$ es una muestra reciente de la fragmentación de la sociedad colombiana y la falta de consensos sobre los principales problemas que aquejan al país, así como sobre las posibles soluciones que deberían ser implementadas, para la creación de futuros compartidos. Tal vez por ello, el Paro Nacional no ha logrado materializar muchas de las demandas ciudadanas. Tampoco ha logrado generar consensos fuertes alrededor de propuestas compartidas, lo que demuestra las dificultades que tenemos como sociedad y como Estado democrático para dialogar y lograr consensos entre diferentes actores. Aún así, el activismo político que vemos presente en las redes sociales cada vez va en aumento $y$, en este orden de ideas, es nuestra responsabilidad analizar estas tendencias presentes en el mundo digital, para efectos de comprender y gestionar de la mejor forma el conflicto presente en nuestros entornos digitales, analógicos y físicos.

En la teoría política, el poder del Estado descansa en la convicción popular de la su propia legitimidad, basado en consensos compartidos entre los miembros, conforme la elección de representantes del pueblo; quienes en principio representan los intereses y valores presentes en las comunidades. Así, los representantes son los encargados de tomar decisiones públicas que afectan al conjunto de la sociedad, según procedimientos y marcos jurídicos prestablecidos que tienen la finalidad de garantizar derechos a todos los miembros de la colectividad. Sin embargo, la representación en ninguna época ha sido perfecta, pues la democracia debe lidiar con diversos problemas, desde la dificultad de que una persona represente a 
millones de ciudadanos, con diferentes creencias y estilos de vida, hasta las dificultades prácticas que tiene el dialogo entre posiciones e intereses encontrados en las comunidades. En este contexto, la era digital nos introduce en nuevos desafíos para la democracia y el Estado, pues ciudadanos que antes no tenían voz ahora la tienen en las redes sociales, blogs y medios de comunicación, con diversos alcances.

Aunque muchas Constituciones Latinoamericanas han adoptado nuevos mecanismos para mejorar la participación política de sectores y grupos históricamente excluidos, estos no han sido suficientes para invertir las dinámicas de poder y las profundas desigualdades que siempre han aquejado a la región. Por ello, no sorprende el estallido de protestas en Chile, Bolivia, Ecuador y Colombia en 2019, pues la inconformidad de amplios sectores de la población debe ser escuchada y sentida por las elites de poder, en una de las regiones más desiguales del planeta.

Sin embargo, estas protestas están lejos de ser inéditas o excepcionales. Alrededor del mundo, desde el 2011, hemos evidenciado un incremento importante en las protestas, en diferentes contextos, pero bajo presupuestos similares, que difícilmente pueden ser controlados por los Estados. Desde la primavera árabe, el movimiento de indignados y Occupy Wall Street, ciudadanos y movimientos sociales alrededor del mundo están utilizando su derecho a la protesta para manifestar su inconformidad con la corrupción, el costo de vida, la desigualdad, la justicia climática o las libertades políticas, entre otros. Aunque las causas de la protesta puedan ser diferentes, un común denominador ha sido la enorme dureza de la respuesta del Estado al momento de contener las manifestaciones sociales, lo que no solo deslegitima su actuación, sino que impide encontrar caminos de dialogo que eviten la violencia desmedida y la violación de los derechos humanos.

El aumento de las protestas año a año y el aumento de la violencia para controlar a los manifestantes causan profundos cuestionamientos al funcionamiento de la democracia representativa y, evidencia la poca capacidad del Estado para responder de forma efectiva a las demandas de la sociedad global e informacional.

En este contexto, el presente artículo busca primero analizar los problemas no resueltos de la democracia representativa, para después en la tercera sección, 
estudiar cómo las protestas y los movimientos sociales del siglo XIX permitieron ampliar la democracia representativa, pero sin resolver los problemas intrínsecos de la representación en sociedades de masa. En la cuarta sección realizaremos algunas reflexiones sobre las reformas constitucionales en América Latina, que buscaron aumentar la participación política, en las últimas décadas del siglo XX; para después tratar el empoderamiento de los movimientos sociales en la sociedad en red. Finalizaremos con algunas conclusiones.

\section{LOS PROBLEMAS NO RESUELTOS DE LA DEMOCRACIA}

\section{REPRESENTATIVA}

En los Estados modernos de los siglos XVIII y XIX, los representantes son necesarios porque los asociados son numerosos y están dispersos en territorios extensos, donde la comunicación es difícil o simplemente es imposible. Así, es necesario que el pueblo elija a los representantes de sus intereses, quienes inicialmente, son presentados como ciudadanos virtuosos, es decir, hombres blancos con propiedad que saben leer y escribir; quienes en principio, tienen gran capacidad de cuidado sobre el interés general de la comunidad. En este sentido, la democracia representativa fue forjada sobre la idea de representantes virtuosos y súper capacitados que siempre tomarán buenas decisiones para la colectividad. Aquí el representante deja de ser un individuo y se convierte en un hacedor del interés general de la colectividad (Valencia-Tello, 2015, 183).

El hipotético "pacto originario" o "contrato social" ayuda a que los individuos puedan salir del "estado de naturaleza" y también ayuda a establecer el carácter convencional del Estado representativo, cuya aceptación o consentimiento hipotético entre todos los individuos, sustenta la legitimidad del poder político, de la ciudadanía y, finalmente, de los representantes del pueblo (Capella, 1997, 117). Estos mitos sobre la democracia representativa fueron fundamentales para la consolidación de los Estados modernos y para la estabilidad de los sistemas políticos alrededor de un imaginario compartido, por ello no debemos desestimar su poder, pues estas ideas fundacionales dan sentido a nuestros sistemas políticos.

No obstante, Capella $(1997,117-118)$ considera que el axioma de la doctrina 
política moderna debe ser contemplada desde diferentes puntos de vista. Primero, él resalta el formalismo que desde un inicio tuvo la democracia representativa, ya que el ideal democrático se sustentaba en un pacto hipotético que en la práctica nunca sucedió, lo que causa que la democracia sea formal y abstracta, hasta idealista, esto es, sin ninguna posibilidad de ser llevada seriamente a la practica. La idealización de la democracia representativa impide ver a la democracia como un proceso, con avances y regresiones en la distribución efectiva del poder entre el pueblo y los gobernantes, pues en la concepción ideal de democracia, el poder ya está previamente distribuido de forma igualitaria entre todos los ciudadanos.

En segundo lugar, al contrario de las democracias antiguas, como la ateniense, que establecía deberes y una cultura social, como condiciones previas para el funcionamiento de la democracia, mediante la existencia de instituciones educativas y militares (para formar al ciudadano y defender la comunidad); en la democracia moderna, la importancia dada al contrato social hipotético, coloca la manutención de los sistemas democráticos, en la capacidad de convicción del discurso sobre la igualdad política abstracta del pueblo y, en consecuencia, los deberes sociales de los ciudadanos aparecen como una consecuencia de los derechos y no como una condición previa para la manutención y el buen funcionamiento de la democracia (Capella,1997, 117-118).

Así, en la democracia moderna, la función formal de la ciudadanía o del pueblo soberano está limitada, en la practica, a la elección de los representantes del pueblo, quienes finalmente van a determinar la "voluntad general" mediante la promulgación de leyes que son votadas por la mayoría de los representantes en el parlamento. Este es un problema que desde el inicio tuvo la democracia representativa, pues desde el siglo XVIII la ciudadanía solo tiene la función de elegir a los mandatarios del Estado, sin que existan herramientas que permitan una mayor participación de la ciudadanía en las elecciones públicas (Rodríguez, 2005, 45).

La democracia representativa se fundamenta en la idea de que el pueblo es el único soberano y el único legitimado para elaborar una Constitución, que debe determinar el marco institucional en el que deben actuar los representantes de la Nación. Aparentemente, el pueblo está compuesto por personas iguales, sin distinción alguna. Pero, en el siglo XVIII, el pueblo con capacidad de participar en los 
procesos políticos se reduce a un pequeño grupo de hombres blancos, que saben leer y escribir y que cuentan con propiedades, razón por la cual la voluntad general representa solo a una pequeña elite del total de la población.

Con base en estos presupuestos, Sieyès $(2008,139,140)$ afirma que el pueblo está legitimado para encargar a los representantes extraordinarios la elaboración de una Constitución que determine claramente los límites que deberían ser respetados por los representantes, quienes tendrán un poder limitado sobre los asuntos de gobierno. Así, para Sieyès el poder delegado jamás puede llegar a ser nocivo para sus mandantes, pues la voluntad general es común a todos los individuos de la nación (Abellán, 2011, 179).

En los Estados Unidos, Madison (2020) describe a los representantes del pueblo como seres sabios y virtuosos que saben discernir mejor sobre los verdaderos intereses del país, y por ello en su concepto, las fracciones dentro de la democracia representan uno de los mayores riesgos. Las fracciones son descritas en el Federalista como un grupo de ciudadanos que, movidos por la pasión común o por el interés, actuaban de forma contraria a los derechos de las minorías y, por tanto, contra los intereses de la comunidad o del bien público. Así, para solucionar el problema de las fracciones, la República debe basarse en la democracia representativa, basada en el voto censitario que excluía buena parte de la población.

Desde la perspectiva de Madison, la exclusión política de ciertos grupos no representa un problema importante, ya que, en su imaginario, los que deseen participar del Parlamento podrán hacerlo, siempre y cuando sean ciudadanos destacados en mérito, inteligencia, propiedades y virtudes. Adicionalmente, pocos ciudadanos se interesan por participar activamente de los asuntos públicos, ya que desde esta época se evidenciaba un abandono o desinterés por parte de los individuos sobre los asuntos públicos, como bien lo registró Tocqueville $(1987,515)$ así:

Como los hombres que viven en los países democráticos no tienen ni superiores ni inferiores, ni asociados habituales y necesarios, ellos de buen agrado se vuelven para si mismos y se consideran individualmente. [...] Por eso, solamente con esfuerzo estos hombres se alejan de sus asuntos particulares para cuidar de los asuntos comunes; y su tendencia natural es 
abandonar ese cuidado exclusivamente al representante visible y permanente de los intereses colectivos, que es el Estado. No solo no tiene un gusto natural por ocuparse de lo público, sino que muchas veces no tiene el tiempo para hacerlo. La vida privada es tan activa en los tiempos democráticos, tan agitada, tan llena de deseos, de trabajos, que casi no resta mas energía, ni paseos a cada hombre para la vida. (Traducción nuestra)

Para Rodríguez (2005, 43), el modelo de democracia representativa propuesto en el Federalista № 10, evidencia una estrategia para neutralizar los "peligros de la mayoría" y sus efectos. Por lo tanto, es una manera de dirigir a la grandes Repúblicas, desde la élite, para contra restar la amenaza de dotar de mecanismos de participación al pueblo. Con relación a la elite del siglo XVIII, Rodríguez afirma:

En efecto, según la interpretación de MADISON previamente señalada e imperante en el siglo XVIII, las minorías están compuestas por los privilegiados por una educación superior y una capacidad económica de grandes proporciones, mientras que las mayorías se conformaban por la gran masa de desposeídos e ignorantes que prevalecen en las sociedades. Así, las medidas implementadas van dirigidas a frenar el poder de las mayorías ignorantes y pobres en beneficio de las minorías ilustradas y económicamente fuertes, con tal suerte que, para los observadores de los siglos XVII y XVIII, los peligros de dominación se ciernen de la mayoría sobre la minoría, pero en el sentido anteriormente anotado (Rodríguez, 2005, 45).

La democracia representativa del siglo XVIII y XIX, dominada por la clase burguesa que representaba solo una minoría, ayudó a construir las instituciones y las normas jurídicas necesarias para la construcción del capitalismo en formación, asegurando a los detentores del capital la preponderancia en la vida económica y en la vida política de los Estados (Ripert, 1947, 23). Al respecto, Capella $(1997,121)$ afirma:

Así, los Estados Unidos de Norteamérica no vacilaron en otorgar poder político a grandes empresas privadas - poniendo unidades militares a las órdenes directas de sus directivos -; 
por ejemplo, a las empresas mineras y ferroviarias, en el último caso para combatir a los amerindios nativos y expulsarles de las tierras que ocupaban inmemorialmente en beneficio de los colonos inmigrantes. La democracia norteamericana no permitía que los indígenas nativos tuvieran no ya derechos políticos, sino siquiera el derecho de propiedad. Los indígenas no podían ser propietarios de tierras ni siquiera cuando les hubiera correspondido ese derecho no ya en la forma tradicional de sus propios sistemas normativos sino incluso cuando procedía por matrimonio o por herencia de un colonizador anglo. El «doble estado» es eso y cosas como ésas: un rasero jurídico distinto para «amigos» y «enemigos», monopolizando el poder sobre la decisión acerca de quién es «amigo».

En el Estado liberal, la democracia representativa dominada por las elites ayuda a fortalecer al sistema capitalista en formación, causando el aumento de las desigualdades entre la elite rica y el resto de la población pobre. La Ley Le Chapelier (1791) en Francia se encarga de extinguir de un solo golpe toda instancia intermedia entre los individuos y los gobernantes, lo que dio vía libre al refuerzo incontrolado de poderes en la cúpula y al centralismo jurídico y político del Estado (Comparato, 2007); pues el pueblo, que se identifica con la nación, tiene la única función pasiva de elegir a sus representantes.

Por esto, Ripert $(1947,25)$ afirma que cuando el legislador anuncia la libertad del comercio y de la industria mediante la ley 2-17 de marzo de 1791, no sólo declaraba un principio fundamental para el nuevo sistema económico, sino que también destruía la vieja sociedad de sociedades. La ley declaró que las asociaciones obligatorias estaban suprimidas y tres meses después las asociaciones libres también estarían prohibidas. Así, un orden social fuerte en el pasado fue destruido por la omnipresencia de la ley. En este sentido, la ley fue útil, no sólo por lo que dio, sino sobre todo, por lo que destruyó.

En el siglo XIX, el Código de Napoleón resolvía el problema del trabajo dependiente utilizando la antigua figura de la locación del derecho romano. Así, se entendía que el individuo, en calidad de propietario de su propia fuerza, ofrece "libremente" su trabajo a otro individuo, contra la prestación de un salario, convirtiendo al trabajo en tan sólo una cosa, regulada por el Código Civil (Grossi, 
$2008,118)$. Aquí no es relevante la desigualdad fáctica existente entre las partes, pues nos encontramos ante un sistema jurídico basado en el axioma de la igualdad formal entre todos los ciudadanos.

La revolución industrial representa un triunfo del capitalismo, que con ayuda de las maquinas, y de normas creadas a la medida de las necesidades, crea las macroempresas, con capacidad de acumular grandes capitales y de contratar a miles de trabajadores, en condiciones infrahumanas. Pero al mismo tiempo, la macroempresa ayuda a evidenciar la fragilidad del sujeto humano, frente a las maquinas y a las injustas condiciones contractuales, basadas en la igualdad formal de las partes (Grossi, 2008, 120).

Por esto, la revolución industrial también fue importante para el retorno de las corporaciones y las asociaciones como instrumentos capaces de intermediar entre el Estado y el individuo y, como instancias de protección personal, cuando las condiciones lo demandan. En este sentido, fueron necesarias numerosas luchas sociales para que el individualismo burgués aceptara la necesidad de leyes sociales que protegieran a la parte más débil de la relación contractual. Poco a poco, las luchas sociales por parte de diversos sectores inician la formación de movimientos sociales bien organizados, con la pretensión de adquirir los derechos políticos antes negados, esto es, adquirir la condición de ciudadanos, con capacidad para elegir y ser elegidos.

\section{LA AMPLIACIÓN DE LA DEMOCRACIA REPRESENTATIVA}

En el siglo XIX, las condiciones que posibilitaron el enriquecimiento de la poderosa burguesía capitalista determinaron también el surgimiento del proletariado, sometido a condiciones infrahumanas de vida y de trabajo, evidenciando que la igualdad formal de los ciudadanos establecida en la ley, contrastaba con las pobres condiciones económicas y sociales que no permitían a los trabajadores tener condiciones de vida digna, ni tener posibilidades de participar en la política, dado que el derecho al sufragio dependía del status social y económico (Rincón, 2004, $66)$.

Las protestas y las huelgas que eran organizadas por los trabajadores para 
exigir mayores derechos, fueron reprimidas fuertemente por el Estado, pues se consideraba que atentaban contra el orden público y contra la libre capacidad de contratación de los patrones, ya que el modelo económico imperante de laissez-faire no permitía la intervención del Estado, y, por lo tanto, la injusticia encontraba su mayor soporte en el ordenamiento jurídico y en el poder del Estado (Rincón, 2004, 67). Los movimientos sociales que se organizaron en este momento se fundamentaban principalmente en el contexto de la lucha de clases, es decir la lucha entre burgueses y proletarios.

Para evitar que la legislación fuera una legislación de clase, John Stuart Mill propuso que se buscara equilibrio entre los intereses de las dos clases sociales existentes de la sociedad industrial, es decir, entre burgueses y proletariados, con el objetivo de lograr que la mayoría parlamentaria necesite siempre del apoyo de la otra clase, para la aprobación de leyes. Para Mill (2001, 123-126), el sistema mayoritario, al dar todo el poder a la mayoría numérica, excluía a las minorías más débiles. Así, una verdadera democracia, implicaba obligatoriamente que las minorías fueran incluidas y tuvieran representación sobre la base de un sufragio proporcional. Para esto, era necesario que cada grupo minoritario tuviera un representante de su propia elección en el Parlamento, para permitir la participación efectiva de las minorías.

Mill rechaza el sufragio restrictivo o censitario por considerarlo injusto y por limitar las posibilidades educativas de la participación política, pero al mismo tiempo, no concuerda con el sufragio universal, ya que el derecho al voto debe tenerlo solo cualquier hombre o mujer que sepa leer, escribir y contar y, que pague impuestos, de forma tal, que son excluidos los analfabetos, los que no pagan impuestos y las personas dependientes de la ayuda social, que son una carga económica para la comunidad. Mill consideraba que los ciudadanos más calificados deberían tener dos o más votos y los demás, solo uno. Al respecto comentó: "No es algo útil, sino dañino, el que la constitución de un país declare que la ignorancia puede reclamar tanto poder político como la sabiduría." (Mill, 2001, 195-199).

Posteriormente, desde el final del siglo XIX y el inicio del siglo $\mathrm{XX}$, los diferentes Estados alrededor del mundo ampliaron los derechos políticos, mediante la institucionalización del sufragio universal en la democracia representativa. Desde 
entonces, la democracia representativa es el sistema político preferido en la mayoría de los Estados alrededor del mundo, por ser un sistema que amplia las posibilidades de la efectiva participación política de los diversos sectores de las sociedades. Aún así, el sufragio universal también trae nuevos problemas a los Estados, debido a la existencia de pluralidad de intereses, que difícilmente pueden ser bien representados en los parlamentos o en las diversas instituciones estatales.

Adicionalmente, el énfasis colocado en el mandato representativo, sobre otros derechos y obligaciones de los ciudadanos, generó un mayor desapego de los ciudadanos en los asuntos públicos, ya que el representante, encargado de decidir sobre la esfera pública, es la persona designada para tomar las decisiones, sin realizar mayores consultas a los ciudadanos desinformados. La única función del ciudadano es elegir cuando tiene derecho al sufragio y, cuando no tiene este derecho, simplemente no existen muchos canales de comunicación entre el Estado y las personas sin el derecho al voto. La idea de que el representante, representa a la nación y no a los electores ayuda a reforzar el mandato representativo, ya que los ciudadanos no cuentan con mecanismos de control efectivos sobre los representantes electos, lo que permite mantener alejado al pueblo de las decisiones públicas tomadas por los representantes.

Así, el fortalecimiento del mandato representativo y la falta de mecanismos de participación ciudadana, hacen que la implantación del sufragio universal no sea suficiente para solucionar los problemas intrínsecos de las democracias representativas.

La falta de participación de la ciudadanía en la democracia representativa moderna lleva a Weber a afirmar que la democracia es simplemente un sistema de libre elección de los dirigentes. Para Weber, la ampliación del sufragio y la igualdad social de la población no impiden que aumente la burocratización del poder político, $y$, por lo tanto, la democracia solo ayuda a nivelar a los gobernados, ya que la democracia no significa necesariamente aumento de la participación activa de los dominados en el poder ${ }^{1}$.

\footnotetext{
${ }^{1}$ Naturalmente hay que tener en cuenta que la palabra "democratización" puede inducir a error. El "demos", en el sentido de una masa inarticulada, no "gobierna" nunca en las sociedades numerosas por sí mismo, sino que es gobernado, cambiando solo la forma de selección de los jefes del gobierno y la proporción de la influencia que puede ejercer o, mejor dicho, que pueden ejercer otros círculos procedentes de su seno, por medio del
} 
Así, la democracia en el sentido liberal de "poder del pueblo" es para Weber una ilusión, pues la masa desorganizada nunca administra una comunidad política de grandes dimensiones, sino que ella es administrada, y lo único que cambia es el modo de seleccionar a los dirigentes encargados de administrar. En la democracia representativa en las sociedades de masa, la única forma de influencia del pueblo sobre los gobernantes es mediante la "opinión pública". Weber $(1963,114)$ esta de acuerdo con el sufragio universal para todos los alemanes, y está a favor de un parlamento fuerte y responsable soportado en la existencia de partidos políticos organizados centralizadamente con capacidad para luchar políticamente.

En el siglo XX, en la medida en que el derecho al voto se amplia, aparecen numerosos partidos políticos con la intensión de ascender al poder para hacer prevalecer los diversos intereses que representaban y, por lo tanto, cada vez, se torna mas evidente que las sociedades no son homogéneas; que existen diversos intereses y grupos de sociales, que también tienen derechos e interés de participar activamente del debate público en el Parlamento. Así, los movimientos sociales que surgirán a lo largo del siglo XX ya no pueden ser enmarcados dentro de la lucha de clases, del siglo pasado, sino que la pluralidad de intereses y organizaciones en la sociedad civil, marcarán nuevos desafíos para generar consensos en sociedades complejas y plurales.

En este contexto y, poco a poco, la democracia de lideres realiza su aparición, proponiendo una concepción de la política como "lucha por el poder", en donde intervienen partidos políticos organizados y lideres políticos responsables que buscan direccionar a la sociedad mediante la imposición de determinas políticas que representaban sus intereses.

Para Schumpeter (1968, 321-342), la democracia es un método de selección de lideres y, por esto critica la idea del "bien común" y la idea de la "voluntad general", por considerar que los individuos no siempre comparten los mismos objetivos y, por el contrario, tienen diferencias irreductibles sobre lo que debe ser la vida y la sociedad. Adicionalmente, Schumpeter considera que las ideas sobre el

complemento de una llamada "opinión pública", sobre el contenido y la dirección de la actividad del gobierno. En el sentido aquí apuntado, la "democratización" no debe significar necesariamente el aumento de la participación activa de los dominados en el dominio dentro de la organización considerada. (WEBER, 1963. 113-114) 
bien común o la voluntad general son peligrosas porque implican obligatoriamente rechazar cualquier discrepancia por sectaria o irracional, es decir, se pierde la libertad de discusión sobre puntos de vista divergentes. Así, la democracia significa solamente que el pueblo tiene la posibilidad de aceptar o rechazar a los hombres que van a gobernar.

La democracia competitiva de Schumpeter $(1968,343)$ acepta la existencia de intereses particulares organizados dentro de la democracia y, en consecuencia, tiene en cuenta la existencia de amplias libertades políticas para todos los individuos, buscando ampliar las posibilidades de discusión sobre los asuntos públicos.

La visión de la democracia como lucha por el poder, o como democracia competitiva va a ser mas evidente al final del siglo XX cuando las nuevas tecnologías cambien totalmente la forma de hacer política en las sociedades de la información (Castells, 2011). Adicionalmente, el fortalecimiento de las organizaciones de la sociedad civil en los diferentes niveles de gobierno va a colocar nuevas presiones sobre los Estados y la democracia, al exigir mayor participación en las decisiones públicas; pero antes de analizar las organizaciones de la sociedad civil, a continuación estudiaremos algunas reformas constitucionales ocurridas en América Latina, que buscaron aumentar la participación política en sociedades de masa a finales del siglo $\mathrm{XX}$.

\section{LAS REFORMAS CONSTITUCIONALES PARA AUMENTAR LA PARTICIPACIÓN POLÍTICA EN AMÉRICA LATINA}

Como fue analizado en las secciones anteriores, las primeras constituciones escritas se basaron en la idea de la existencia de una unidad nacional que permitía establecer claramente el interés general del la nación, esto es, la ideología imperante, en las leyes aplicables a todos. En un comienzo, la población no cuestionó de forma relevante la democracia representativa o la ley; los cuestionamientos comenzaron a surgir a medida que los diversos grupos sociales evidenciaron las injusticias y la falta de representación dentro de los sistemas políticos. Así, la aparente unidad nacional comenzó a fragmentarse con el surgimiento del pluralismo en las sociedades, con diferentes conceptos de vida, valores y finalidades en la esfera pública y privada. 
El reconocimiento de la existencia de pluralidad de intereses en las sociedades provoca fuertes cuestionamientos sobre la democracia representativa, pues, en la practica, existen innumerables dificultades para que todos los intereses estén bien representados en el parlamento de los Estados. El sufragio universal permite que la representación en las sociedades se amplíe, pero también constituye un desafío para los Estados, que deben construir consensos entre intereses divergentes.

En América Latina las últimas reformas de los textos constitucionales modificaron substancialmente el presupuesto de la unidad nacional de los Estados, introduciendo y reconociendo el pluralismo existente en la población. Muchas Constituciones definen sus naciones como pluriétnicas y pluriculturales y establecen como principio constitucional la promoción de la diversidad².

El reconocimiento de la multiculturalidad y de las competencias propias de las jurisdicciones indígenas, junto con la abertura al derecho internacional de los derechos humanos, causa erosiones profundas en el sistema tradicional de fuentes jurídicas y en el papel central que anteriormente tenían la ley y la reglamentación gubernamental en los ordenamientos jurídicos nacionales. En la actualidad, las fuentes del Derecho se han multiplicado, causando el aumento de la complejidad del Derecho, ya que ahora no es suficiente consultar la ley, sino que también es importante consultar las normativas de los derechos humanos en el derecho internacional, junto con los reconocimientos realizados en las Constituciones a los grupos minoritarios, como los pueblos indígenas (Uprimny, 2011, 114).

Las reformas constitucionales también buscaron aumentar los mecanismos de participación ciudadana, los cuales no se limitaron a la democracia representativa, sino que buscaron incluir algunos mecanismos de democracia directa, tales como las consultas populares y los referendos ${ }^{3}$, así como también la creación de instancias ciudadanas de control sobre la gestión pública, como pueden

\footnotetext{
${ }^{2}$ Artículo 7 de la Constitución colombiana, artículo 215 de la Constitución brasilera, artículo 1 de la Constitución bolivariana y artículo 2 numeral 19 de la Constitución peruana. (Uprimmy. 2011,111-112)

${ }^{3}$ Por ejemplo, la Constitución colombiana incorporó el plebiscito, el referendo, la consulta popular, el cabildo abierto y la revocatoria del mandato. Véanse artículos 103 y ss. de esa Constitución. Igualmente, la Constitución venezolana prevé en su artículo 70 la participación ciudadana mediante la elección de cargos públicos, el referendo, la consulta popular, la revocatoria del mandato, la iniciativa legislativa, constitucional y constituyente, el cabildo abierto y la asamblea de ciudadanos y ciudadanas. En Ecuador se consagró la consulta popular y la revocatoria del mandato en los artículos 103 y 113 de su Constitución. Uprimmy. 2011, p, 117 .
} 
ser las asociaciones de usuarios que supervisan la gestión de las empresas de servicios público s(Uprimny, 2011, 114). En todo caso, las posibilidades de garantizar la participación de todos los ciudadanos, en la deliberación de los asuntos públicos, continúa siendo una utopía, limitada por los tiempos, los costos y la voluntad política de las administraciones públicas.

Aún así, es importante resaltar que la mayoría de las reformas constitucionales buscaron reducir ciertas facultades presidenciales e incrementar la capacidad de control y de decisión de los congresos. Sin embargo, paradójicamente, fueron aprobadas también la posibilidad de reelección inmediata del Presidente, con la finalidad de elegir gobernantes carismáticos, tal como sucedió en Argentina con Menem, en el Brasil con Cardoso y Lula, en el Perú con Fujimori, en Colombia con Uribe y Santos y, en Venezuela con Chávez y Maduro (Uprimny, 2011, 120-121). Como resultado, la región no ha podido eliminar los sistemas de gobierno fuertemente presidencialistas que suelen evitar las criticas y la participación de grupos contradictores, centralizando el poder en unos pocos con capacidad de mando y control.

Por esto, para Uprimmy $(2011,123)$, en América Latina, aunque las reformas constitucionales buscaron fortalecer la democracia y combatir las exclusiones y las inequidades sociales, étnicas y de genero, proponiendo una democracia inclusiva capaz de incorporar sectores tradicionalmente excluidos de las sociedades, mediante mecanismos de democracia directa que complementan la democracia representativa; en la práctica, estas reformas se han mostrado insuficientes para cumplir con el propósito de combatir exclusiones e inequidades sociales.

No obstante, para Boaventura de Sousa Santos $(2010,110)$, las Constituciones latinoamericanas son "transformadoras" y la "democracia es intercultural", porque en América Latina se articulan la democracia representativa, participativa y comunal $y$, por lo tanto, él considera que se trata de "una de las formulaciones constitucionales sobre democracia más avanzada del mundo".

Sin embargo, en la práctica, las reformas constitucionales en muchos casos se han mostrado poco eficaces, al momento de reducir las desigualdades y permitir mayor participación de sectores históricamente excluidos. Concretamente, estas reformas no detuvieron los problemas inherentes de la democracia representativa, 
tampoco resolvieron los problemas relacionados a la formación de consensos entre diversos grupos de interés, con diversas concepciones de vida y de valores, causando profundos cuestionamientos sobre los ordenamientos jurídicos y la representación en los Estados.

En Estados Unidos, Dahl (2000, 373-374) demuestra que en las sociedades no existe un único centro de poder, sino que el poder está disperso en el conjunto de la sociedad, y, por lo tanto, las decisiones que toman los gobiernos ocurren dentro de un complejo mundo de negociaciones e influencias de distintos y diversos grupos sociales, y no solo de los partidos políticos tradicionales. Para Dahl, una democracia es estable cuando existe consenso social sobre las reglas de juego político y la amplitud de las opciones políticas permitidas para actuar en la política.

Aún así, en la actualidad no existen mecanismos o procedimientos claros y simples que permitan garantizar la realización legitima de consensos entre diferentes intereses o grupos sociales, con diferentes ideologías, lo que contrasta con los grandes avances tecnológicos realizados en la era de la globalización en materia de comunicación e información.

Aunque importantes autores como Habermas (1997, 9-19) trabajen arduamente en el concepto de democracia deliberativa como método para la formación de la voluntad en la toma de decisiones, él reconoce que la creación legitima del Derecho depende de las condiciones existentes en los procesos y presupuestos de la comunicación, en donde la visión republicana (de formación de la opinión y de la voluntad de las personas privadas) es fundamental para la construcción de una sociedad estructurada políticamente. Así, uno de los presupuestos fundamentales de la comunicación para la formación política es la visión republicana, aunque esta visión también cuente con algunos elementos liberales.

Habermas (2000) también reconoce los problemas derivados de la globalización, lo que denomina "la constelación postnacional" para el proceso de legitimidad democrática, ya que la constitución es nacional, pero las fuentes del poder están cada vez más en la esfera supranacional. Adicionalmente, la teoría de la democracia deliberativa no tiene en consideración la existencia de nuevos y poderosos medios de comunicación globales que cambian de forma importante los 
presupuestos de la comunicación en la era de la globalización y las nuevas tecnologías.

Así, contamos con poderosas tecnologías que facilitan y agilizan las formas de comunicación entre individuos, grupos y redes locales y globales, pero, al mismo tiempo, contamos con profundas limitaciones sociales para que la comunicación sea efectiva y obtenga consensos importantes sobre el direccionamiento que deberíamos dar a nuestras sociedades. A continuación analizaremos las transformaciones sucedidas sobre los movimientos sociales en las últimas décadas.

\section{MOVIMIENTOS SOCIALES EN LA SOCIEDAD EN RED}

La sociedad en red, se caracteriza por construir una cultura de la virtualidad, mediante la constitución de espacios de flujos y del tiempo atemporales a nivel global; por ello, evidencia una nueva forma de organización social que transforma las identidades individuales y colectivas, la cultura y las instituciones existentes del mundo moderno. Sobre el particular, Castells $(2008,91,92)$ afirma:

La globalización y la informalización, instituidas por las redes de riqueza, tecnología y poder, están transformando nuestro mundo. Están ampliando nuestra capacidad productiva, nuestra creatividad cultural y nuestro potencial de comunicación. Al mismo tiempo, están privando de sus derechos ciudadanos a las sociedades. Como las instituciones del estado y las organizaciones de la sociedad civil se basan en la cultura, la historia y la geografía, la aceleración repentina del tiempo histórico y la abstracción del poder en una red de ordenadores están desintegrando los mecanismos de control social y representación política existentes.

En este sentido, si en el siglo XX teníamos problemas con la representación política; en el siglo XXI, las redes sociales y la auto-comunicación de masa en entornos digitales crea nuevos desafíos de difícil solución. La auto-comunicación de masas, termino acuñado por Castells $(2011,88)$, describe una nueva forma de comunicación propiciada por las nuevas tecnologías de la información; donde cualquier persona puede llegar a la audiencia mundial, publicando información en la red en paginas como YouTube, Facebook, y en blogs, o enviando correos 
electrónicos a una enorme lista de contactos. La auto-comunicación de masas permite comunicar todo tipo de información sin que exista ningún tipo de control centralizado sobre la información, otorgando así total libertad tanto a los emisores como a los receptores para emitir y recibir información y comunicar de forma descentralizada.

En consecuencia, las nuevas tecnologías multimedia permiten comunicar todo tipo de información (tanto la mejor como la peor) a millones de personas alrededor del mundo, interconectando las personas en tiempo real mediante la emisión de mensajes que pueden propagarse rápidamente sin que los emisores de las mensajes o cualquier otro actor puedan controlar los efectos que la información pueda tener en las comunidades, en los Estados o en el mundo.

La gran novedad es que todas las formas de comunicación se articulan en un hipertexto digital, interactivo y complejo que integra en su diversidad las distintas expresiones culturales producidas por la interacción humana, esto es, tanto las mejores como las peores (Castells, 2011, 88).

En este contexto, Castells (2008, 92, 93) propone que los movimientos sociales deben ser comprendidos en sus propios términos, es decir, los movimientos son lo que dicen ser. Esto porque sus prácticas y en especial sus discursos son su definición. Así se evita la complicada tarea de interpretar el "verdadero" discurso de los movimientos. Por esto, los movimientos pueden ser socialmente conservadores o revolucionarios, ambas cosas a la vez o ninguna, pues no existe una direccionalidad predeterminada en la evolución social y el "único sentido de la historia es la historia que sentimos". Por lo tanto, para Castells $(2008,94)$ no hay movimientos malos o buenos, todos son síntomas de nuestras sociedades y todos chocan con las estructuras sociales con diferentes intensidades.

Los movimientos sociales que han surgido en la ultima década, son formados mediante la comunicación de mensajes de rabia y esperanza, para convocar protestas contra el sistema, y las instituciones, sin que los grupos tengan objetivos o propuestas claras sobre lo que debe ser hecho. Las redes sociales se tornan espacio público para compartir ideas y valores que los grupos respaldan o combaten. Las protestas pueden ser organizadas rápidamente por las redes sociales para manifestar molestias sobre diferentes situaciones o realidades que deben 
cambiar, aunque los manifestantes no estén de acuerdo sobre la forma como deben llevarse a cabo los cambios.

Así, por la primera vez en la historia de la humanidad es posible la organización de movimientos en masa sin necesidad de vinculación previa entre los manifestantes, es decir, sin necesidad de vinculación a asociaciones, sindicatos o partidos políticos. Las redes sociales en la actualidad están respondiendo y cuestionando fuertemente al Estado, la democracia, las empresas y a las organizaciones internacionales, solicitando mayor inclusión, participación e información sobre aspectos centrales de interés para las comunidades, y demandando el fortalecimiento de la democracia a favor del pueblo (Valencia \& Diniz, 2013).

Diferentes formas de comunicación pueden ser utilizadas por los movimientos sociales, desde mensajes de texto vía celular, correos electrónicos, Facebook, hasta Twitter. En todos los casos, los movimientos se caracterizan por ser espontáneos y carecer de liderazgos centralizados en alguna persona o grupo concreto, ya que las convocatorias son realizadas simultáneamente por millones de personas, usando sus listas de contactos. Al analizar las protestas iniciadas en diferentes partes del mundo en 2011, Castells (2012, 20) afirma:

Empezó en las redes sociales de Internet, que son espacios de autonomía en gran medida fuera del control de gobiernos y corporaciones que, a lo largo de la historia, han monopolizado los canales de comunicación como cimiento de su poder. Compartiendo dolor y esperanza en el espacio público de la red, conectándose entre sí e imaginando proyectos de distintos orígenes, los individuos formaron redes sin tener en cuenta sus opiniones personales ni su afiliación. (...) Desde la seguridad del ciberespacio, gente de toda edad y condición se atrevió a ocupar el espacio urbano, en una cita a ciegas con el destino que querían forjar, reclamando su derecho a hacer historia - su historia- en una demostración de la conciencia de sí mismos que siempre han caracterizado los grandes movimientos sociales.

Evidentemente, desde 2011 hemos visto el surgimiento de diversos movimientos sociales convocados desde las redes sociales, que han afectado seriamente a los Estados, las empresas y las sociedades. Movimientos como la primavera árabe, los indignados y las protestas de 2013 en Turquía y Brasil, marcan 
una nueva forma de hacer política en el mundo digital. Nuevas olas de protestas han surgido en los últimos años, siendo las más recientes las de 2019 en Hong Kong, Francia, Argelia, Líbano, Colombia, Chile, Bolivia y Ecuador, solo para dar algunos ejemplos.

Desafortunadamente, las últimas protestas han estado marcadas por el uso desmedido de la fuerza y la violencia, causando numerosas muertes, heridos y detenciones masivas por parte de los Estados, que cada vez utilizan técnicas más letales para reprimir las manifestaciones. En todos los casos las protestas tienen en común la ausencia de lideres carismáticos y la horizontalidad de las manifestaciones. Para verificar el alcance global de estos movimientos, pero también los diferentes efectos que pueden generar en cada país, a continuación analizaremos algunos de ellos, iniciando con la primavera árabe, teniendo en cuenta los cambios radicales que generó en las estructuras de poder tradicionales.

\subsection{La primavera árabe}

La primavera árabe inicia en una pequeña ciudad de 40.000 habitantes del centro de Tunez, Sidi Buzid, cuando el 17 de diciembre de 2010, Mohamed Buazizi, un vendedor ambulante de 26 años decide inmolarse ante un edificio del gobierno, para protestar por la confiscación de su puesto de frutas, por la policía local, ante su negativa de pagar un soborno. Su primo Alí grabó la protesta y colgó el video en internet. Aunque Mohamed murió el 3 de enero de 2011, en pocos días se iniciaron manifestaciones espontaneas a pesar de la brutal represión policial que mató al menos 147 personas e hirió a cientos de ellas (Castells, 2012, 38, 39). Las protestas fueron convocadas por las principales redes sociales, en especial Facebook y Twitter. Por las características de los canales de comunicación, fueron los más jóvenes los que dedicaron mayor tiempo a difundir las protestas y convocar más personas a participar activamente de ellas. No obstante, aunque los jóvenes instaran las protestas, ellos no fueron los principales beneficiarios de ellas (BBC Mundo, 2011).

La rabia y la frustración compartidas por ciudadanos de diferentes países árabes desencadenaron más protestas contra regímenes autoritarios y poco 
democráticos. En pocos días, ciudadanos de Argelia, Líbano, Jordania, Mauritania, Sudan, Omán, Arabia Saudita, Egipto, Siria, Yemen, Irak, Somalia, Bahrein, Libia, Kuwait y Marruecos protestaran contra los gobiernos, exigiendo regímenes más democráticos y participativos.

Aunque la rabia y la frustración unan a los países árabes, las protestas tuvieron consecuencias diferentes en cada país, lo que evidencia las profundas disparidades existentes entre los Estados árabes. Aquí mostraremos de forma general los casos más relevantes, para verificar el poder de los movimientos sociales en la actualidad, aunque los cambios iniciados por las protestas no sean controlados totalmente por ninguno de los actores y la inestabilidad política de los países sea la regla en la actualidad.

Comenzando con el caso de Túnez, en octubre de 2011 fueron realizadas nuevas elecciones para los cargos de representación, lo que fue evaluado por algunos como un paso importante para la instauración de la democracia en este país. Pero las evidentes divisiones internas entre los principales partidos políticos y el asesinato de un importante líder de la oposición, en febrero de 2013, muestran que las tensiones internas todavía no desaparecieron (BBC Mundo D, 2013).

En Egipto las protestas iniciaron el 25 de enero de 2011 y se prorrogaron por 18 días. El 28 de enero el gobierno egipcio decidió cortar completamente el acceso a internet para impedir que los manifestantes se organizaran por medio de las redes sociales. Al siguiente día, millones de personas protestaban en las calles de las principales ciudades de Egipto y finalmente el presidente Mubarak se vio obligado a demitir la Presidencia y ceder el poder al Consejo Supremo de las Fuerzas Armadas. Las primeras elecciones democráticas realizadas en 30 años, dejaron al partido islamista en el poder y a Mohamed Morsi en la Presidencia (BBC Mundo D, 2013). Sin embargo, las protestas continuaron en Egipto, y en junio de 2013 el primer presidente electo democráticamente fue depuesto después de solo un año en el poder, causando gran inestabilidad política y profundos cuestionamientos sobre las posibilidades de ejercer la política de forma democrática y pacifica en países con partidos islámicos radicales (BBC Mundo C, 2013).

En Libia, el Presidente Muamar Gadafi quien estuvo en el poder por 43 años fue depuesto después de un conflicto de ocho meses (desde que se iniciaran las 
primeras protestas), no sin antes dejar un elevado numero de muertos en el país. El gobierno interino y el Consejo Nacional de Transición que están en el poder han enfrentado diferentes grupos que apoyaban a Gadafi. En septiembre de 2012 el embajador de los Estados Unidos fue asesinado en Benghazi (la segunda ciudad de este país), a causa de un video publicado en Youtube que se burlaba del profeta Mahoma, causando una nueva ola de protestas en los países árabes (BBC Mundo C, 2013).

En Siria, el levantamiento popular contra el Presidente Bashar al Asad, heredero del partido que gobierna a Siria desde 1947, dejó más de 60.000 muertos y 2.5 millones de refugiados en países vecinos en 23 meses de conflictos. Varias iniciativas de paz de la ONU fracasaron, y aunque varios Estados occidentales exigen la renuncia del Presidente Asad y, adicionalmente, piden al Consejo de Seguridad de la ONU la intervención del país, el veto de Rusia y China han impedido la intervención del Consejo de Seguridad en Siria (BBC Mundo C, 2013).

Por el momento, dos características de la primavera árabe deben resaltarse. Primero, la primavera árabe inició como un movimiento social ayudado por las nuevas tecnologías de la información, sin ninguna programación, objetivo o líder específico. Segundo, desde el inicio de la primavera árabe, el movimiento ha depuesto gobiernos que estuvieron en el poder por décadas, provocando innumerables conflictos y muertes en los Estados árabes, donde todavía no consiguen identificar vías pacificas y democráticas para el ejercicio del poder.

\subsection{Los indignados}

Paralelamente, en los países occidentales, el movimiento de los indignados, inició en España, el 15 de mayo de 2011. A partir del sitio Web: www.democraciarealya.es, y con el apoyo de diferentes redes sociales, convocó a millones de personas para realizar manifestaciones pacificas. Los ciudadanos interesados en expresar su opinión, sin intermediación de partidos políticos o sindicatos, salieron a las calles para expresar su indignación contra todo el sistema. Pero no había propuestas especificas para cambiar el sistema o derrocar el capitalismo, puesto que no había consenso sobre que tipo de economía 
proporcionaría condiciones de vida decentes a todos, de forma sostenible y ética. Bajo el lema "no nos representan", no reconocían a ningún partido político o representante como su interlocutor. Ni siquiera tenían un portavoz reconocido.

Por ello, Castells $(2012,115,145)$ afirma que "la red se convirtió en sujeto". Inicialmente, las decisiones de la asamblea tenían un poder simbólico, ya que cada persona era libre de tomar su propia decisión. Sin embargo, el problema principal era siempre cómo llegar a una decisión consensuada, después de largos debates respetuosos. Con el tiempo, fue evidente que era imposible mantener la ocupación de los espacios públicos indefinidamente, no solo por los problemas logísticos sino también por el acoso policial. Adicionalmente solo los activistas de tiempo completo podían participar en las asambleas y gestionar las diferentes tareas que la actividad pública exige.

Posteriormente, este movimiento convocó a nuevas protestas el 15 de octubre de 2011 y, en respuesta, ciudadanos de 960 ciudades en 82 países de todo el mundo expresaron su indignación ante los gobiernos y las corporaciones, protestando contra la crisis económica, el sistema bancario, las desigualdades, la corrupción, la falta de empleo y la falta de representatividad de la clase política, que cada vez pierde más la confianza de la población. Aunque las manifestaciones alcanzaron varios Estados, y las inconformidades de las personas fueran evidentes, los indignados no pudieron presentar propuestas claras o realizables, razón por la cual las demandas de la población no tuvieron mayores efectos en los gobiernos y las corporaciones.

No obstante, Castells $(2012,146-148)$ resalta que la trasformación más importante de estos movimientos sociales se estaba produciendo en las mentes, pues si las personas se unen por sentimientos de indignación y esperanza, la sociedad cambiará en algún momento. Sin embargo, todavía debemos explorar las formas de conectar los sentimientos con las acciones para que estas representen un cambio material en la vida de las personas y en las instituciones, pues de esto se trata la nueva política, que debe estar más interesada en el proceso que en el producto final.

\subsection{Occupy Wall Street}


Para Stiglitz (2012, 24-33), el mensaje de Occupy Wall Street, movimiento que inició en septiembre de 2011 es que no podemos mantener un sistema de mercado abierto y globalizado, por lo menos no en la forma en que lo conocemos, si este sistema da lugar a que los ciudadanos sean más pobres cada año. Para los jóvenes indignados y los manifestantes de otros lugares del mundo, el capitalismo no solo no está cumpliendo lo que prometía, sino que está dando lugar a lo que no prometía, esto es, desigualdad, contaminación, desempleo, y degradación de valores, al extremo en que todo es aceptable y nadie se hace responsable.

La mayoría de los participantes en los campamentos eran jóvenes profesionales y estudiantes, que aunque trabajaban y tenían ingresos medios, se encontraban inconformes con su situación laboral y económica. Solo un quinto de los manifestantes dormía en los campamentos y pronto, la mayoría de los campamentos se convirtieron en refugio de gente sin hogar, que encontraba comida, techo y protección. Las amenazas de acción policial contra las ocupaciones, fueron alertadas por diversas redes sociales ayudando a la protección de los integrantes del movimiento. Al igual que el movimiento de indignados, los ocupantes no querían reproducir en la práctica la democracia formal y el liderazgo personalizado. Crearon su sitio Web para informar sobre la organización sin liderazgo, donde existieron diferentes experiencias organizativas para la toma de decisiones colectivas. Sin embargo como en los otros movimientos, no lograron grandes cambios políticos, aunque si lograron algunas reivindicaciones parciales sobre prácticas injustas como reducciones sobre créditos hipotecarios injustos (Castells, 2012, 157-190).

\subsection{Protestas de Turquía y Brasil en 2013}

Con relación a las protestas iniciadas en 2013 en Turquía y Brasil, varios elementos marcaron similitudes entre estos movimientos sociales, aunque las causas de las protestas fueran diferentes. Entre las similitudes encontramos, primero, que una acción del gobierno considerada injusta por un grupo de ciudadanos (en el caso de Turquía la decisión de construir un shopping en el parque Gezi y en el caso de Brasil la decisión de aumentar la tarifa del bus en $\mathrm{R} \$ 0.30$ ) fue el despertar de diversas inconformidades latentes en la población, causando el levantamiento de protestas masivas por parte de diferentes grupos, los cuales, en principio, no tenían relación alguna con el motivo inicial de la protesta (BBC Mundo 
B, 2013).

Segundo, las redes sociales fueron fundamentales para organizar rápidamente las protestas, reaccionar contra la represión y emprender una guerra efectiva de mensajes en la red, que dejaron en ridículo los tradicionales medios de comunicación, quienes al inicio evitaron informar a la opinión pública sobre las protestas. Tercero, la reacción desproporcionada de la fuerza pública causó mucha indignación en los manifestantes alrededor del mundo, ya que las imágenes de brutalidad policial fueron distribuidas rápidamente por las redes sociales. Finalmente, la existencia de varios símbolos comunes en las protestas, como las mascaras de Guy Fawkes, las tiendas de campaña y los cascos improvisados para evitar los efectos del gas lacrimógeno, pueden encontrarse en las manifestaciones tanto en Turquía como en Brasil (BBC Mundo B, 2013).

Para el periodista Paul Manson, quien viene informando por más de treinta años sobre situaciones de control del orden público por medios "no letales", el uso de gas lacrimógeno, bolillos y cañones de agua están llevando los procedimientos policiales a niveles "cercanos a letales", los cuales son cada vez más inaceptables para los manifestantes que salen a las calles sin intensiones violentas (BBC Mundo B, 2013).

Evidentemente, el uso de gas lacrimógeno ha sido una herramienta central para el Estado en el control de las multitudes de manifestantes en protestas alrededor el mundo, en las últimas décadas. Al respecto, la investigadora Anna Feigenbaum, de la Universidad de Bournemouth, en Inglaterra, muestra como los presupuestos de diferentes países han aumentado de forma importante el presupuesto en materiales contra disturbios, aunque, en momentos de crisis, se contemplen reducciones presupuestales en todas las otras áreas (BBC Mundo A, 2013).

\subsection{Protestas de 2019}

El 2019 ha un sido un año de protestas alrededor del mundo. Ciudadanos de diferentes continentes han salido a manifestarse contra la corrupción, la desigualdad, la falta de oportunidades laborales, el costo de vida, la crisis 
medioambiental y un largo etc. Esto evidencia que los gobiernos no han dado respuestas efectivas a las inconformidades manifestadas en años anteriores por los ciudadanos. La democracia representativa y las instituciones estatales no han podido encausar hasta el momento las diversas demandas presentes en las sociedades y, por la intensidad de las protestas, es claro que el distanciamiento entre el pueblo y el Estado es cada vez mayor.

Según Amnistía Internacional, en América un total de 210 personas murieron violentamente en medio de las protestas, 83 en Haiti, 47 en Venezuela, 35 en Bolivia, 31 en Chile, 8 en Ecuador y 6 en Honduras. En Colombia aunque las protestas no dejaron muertos, es el país donde son asesinados más lideres sociales con al menos 106 asesinatos en 2019 (Amnesty International C, 2020). Las protestas han dejado muchos ciudadanos heridos donde resalta el caso de Chile que reportó 405 personas con lesiones oculares, de las cuales 33 tuvieron estallido o pérdida del órgano. En total 3.648 personas presentaron lesiones, entre ellos 2063 personas fueron heridas por arma de fuego. Un total de 9.129 personas fueron detenidas, de las cuales $87 \%$ son adultos y $12 \%$ son niñas, niños y adolescentes. Se constataron violaciones a los derechos humanos contra los detenidos en las comisarias, por uso excesivo de la fuerza y por 194 casos de acoso/violencia sexual, de los cuales 179 corresponden a desnudamientos. Otras formas de tortura y tratos crueles e inhumanos ascienden a 336 (Chile, 2020)

En Oriente Medio y el Norte de Africa, la brutalidad policial ha sido aún peor para disuadir a los manifestantes utilizando violencia letal, las detenciones arbitrarias y amenazas. En Irak Amnistía Internacional reporta al menos 500 muertos y resalta la enorme resistencia de los manifestantes. En Iran, los reporteros han informado de más de 300 muertes y miles de personas heridas entre el 15 y el 18 de noviembre de 2019. Muchos fueron arrestados, desaparecidos y torturados. En Palestina también se han reportado asesinatos por parte de las fuerzas israelíes. En Argelia, las protestas derrocaron al Presidente Abdelaziz Bouteflika después de 20 años en el poder aunque también fueron reportadas masivas detenciones arbitrarias y muertes. En Egipto las protestas de septiembre causaron un arresto masivo de aproximadamente 4.000 ciudadanos. El informe de Amnistía reporta que en 12 países de la región 136 personas fueron arrestadas por compartir información en línea. Las autoridades también utilizaron su poder para detener el acceso a 
información en internet. En Iran las autoridades apagaron el internet para evitar que las personas compartieran fotos y videos, debido a la cantidad de muertos que dejaron las protestas. En Egipto las autoridades bloquearon las aplicaciones de mensajes para evitar las protestas (Amnesty International A, 2020).

En Europa, las manifestaciones se presentaron en Francia, España, Austria, Polonia, Rumania, República Checa y Hungria. Los ciudadanos protestaban contra las medidas de austeridad y en favor de la justicia social, pero también contra la corrupción, el cambio climático y la independencia del poder judicial. En Francia, España y Austria cientos de personas resultaron heridas en las protestas. La policía hizo uso ilegitimo de la fuerza en Francia y Turquía. Los Estados no exigieron rendición de cuentas a las fuerzas de seguridad por la violencia ejercida durante las manifestaciones. Algunos Estados también reforzaron las atribuciones de la policía, como en Alemania. En respuesta, algunos tribunales tuvieron un papel decisivo en la salvaguardia de las libertades individuales, anulando prohibiciones generales de manifestaciones o haciendo respetar los derechos de los manifestantes (Amnistía Internacional B, 2020)

Los anteriores casos reportados en diferentes países del mundo demuestran el aumento en los últimos años del uso de la fuerza en las diferentes democracias alrededor del mundo y la falta de capacidad del Estado y de la democracia representativa tradicional para responder por vías pacificas a las demandas e inconformidades de los ciudadanos.

El aumento de las protestas año a año y el aumento de la violencia para controlar a los manifestantes causan profundos cuestionamientos al funcionamiento de la democracia representativa en la era de la globalización y las nuevas tecnologías y, evidencia la poca capacidad del Estado para responder de forma efectiva a las demandas de la sociedad global e informacional. Así mismo, evidencia las limitaciones existentes en las principales instituciones estatales para incluir en sus decisiones ciudadanos informados, con voluntad de participar del debate público y abre la puerta para que se analicen cuales formas de participación son factibles en la actualidad con las nuevas tecnologías de la información. 


\section{CONSIDERACIONES FINALES}

El proceso de globalización que inicialmente fue promovido por intereses económicos para generar un mercado abierto, con ayuda de nuevas tecnologías que permiten la interconexión de personas de forma digital, ha causado profundas transformaciones en las personas y los territorios alrededor del mundo, en formas que todavía desconocemos pero que están impactando fuertemente las instituciones tradicionales que organizaban las sociedades en el pasado.

El mundo digital y el fortalecimiento del capitalismo a nivel global ha introducido una nueva forma de sociedad organizada en red caracterizada por su flexibilidad e inestabilidad, frente a la cual las instituciones estables como el Estado y las corporaciones no han sabido responder a las nuevas demandas de forma constructiva y participativa.

Los viejos problemas de la democracia representativa siguen más vigentes que en el pasado, pues en un mundo de billones de personas, los diversos intereses, valores y perspectivas de vida chocan sin mayores consensos para encontrar caminos de dialogo y de acuerdo para futuros compartidos.

La existencia de injusticas presentes desde siempre en nuestras sociedades, tales como la corrupción, la desigualdad o la degradación del medio ambiente, son más evidentes en el siglo XXI, no solo por el gran impacto que tienen en la vida de billones de personas sino también por la existencia de redes sociales que traspasan las fronteras de los Estados, compartiendo información instantánea y generando la indignación de las masas, dentro de un nuevo modelo de comunicación descentralizado sobre el cual los Estados y las corporaciones no tienen más el control.

La incapacidad de los ciudadanos y de las instituciones para encausar las diferentes demandas presentes en las sociedades, deslegitima constantemente la acción pública del Estado y el gran riesgo presente es el retorno de la violencia y los autoritarismos para tratar de disuadir a las masas. Pero el mundo digital en red cambia los equilibrios de poder y transforma como nunca la mente y los sentimientos de los individuos, causando un cambio cultural a gran escala sobre el cual debemos seguir investigando. 
Todavía es muy pronto para evaluar acertadamente los efectos que la cultura digital pueda tener en nuestras sociedades y gobiernos, pero lo cierto hasta el momento es que urge encontrar caminos de dialogo y de consenso en la esfera pública que incluyan a todos los actores interesados, para efectos de utilizar vías institucionales y democráticas que legitimen la acción pública alrededor de ideas compartidas. Talvez estamos en un momento crucial en la historia de la humanidad que requiere de todo nuestro cuidado para evitar caer en viejos autoritarismos. Así, es necesario comenzar a realizar ajustes institucionales sobre las diferentes administraciones públicas para probar diversos mecanismos de inclusión y participación de las comunidades en la toma de decisiones.

En este sentido, las protestas generadas en los últimos tiempos, deben ser tomadas en serio por los Estados, las corporaciones y las organizaciones internacionales, quienes deben procurar mejorar los canales de comunicación con la sociedad, realizando los cambios y ajustes necesarios en las estructuras y en la cultura política y organizacional de las instituciones, buscando promover la participación y la transparencia en las decisiones públicas que afectan a todos, con la finalidad de modificar las relaciones de poder en las sociedades digitales, antes que la indignación y la rabia compartida de los ciudadanos cause protestas masivas que deslegitimen al sistema en conjunto, afectando seriamente la gobernabilidad en nuestras sociedades.

\section{REFERENCIAS}

ABELLÁN, Joaquín. Democracia. Conceptos políticos fundamentales. Madrid: Alianza. 2011.

AMNESTY INTERNATIONAL. A MENA: Renewed wave of mass uprisings met with brutality and repression during "year of defiance". Disponible en: https://www.amnesty.org/en/latest/news/2020/02/mena-renewed-wave-of-massuprisings-met-with-brutality-and-repression-during-year-of-defiance/ Fechas de Consulta: 10/05/2020

AMNISTÍA INTERNACIONAL. B Perspectiva Regional: Europa. 2019. Disponible en: https://www.amnesty.org/download/Documents/EUR0120982020SPANISH.pdf Fecha de Consulta: 10/05/2020

AMNESTY INTERNATIONAL. C Americas: States cracked down on asylum and the right to protest in 2019. Disponible en: https://www.amnesty.org/en/latest/news/2020/02/americas-states-cracked-down-onasylum-and-the-right-to-protest-in-2019/ Fecha de consulta: 10/05/2020 
BBC MUNDO. Cinco mitos de la Primavera Árabe. Disponible en: http://www.bbc.co.uk/mundo/noticias/2011/12/111204 mitos primavera arabe crz.sh $\underline{\mathrm{tml}}$ Fecha de Consulta: 27/12/2011.

BBC MUNDO. A El gas lacrimógeno, un negocio en alza. Disponible en: http://www.bbc.co.uk/mundo/noticias/2013/06/130618 gas lacrimogeno am.shtml Fecha de Consulta: 19/06/2013

BBC MUNDO. B Brasil y Turquía: diferentes protestas con los mismos símbolos. Disponible en: http://www.bbc.co.uk/mundo/noticias/2013/06/130620 brasil protesta simbolos.sht $\mathrm{ml}$

Fecha de consulta: 20/06/2013

BBC MUNDO. C ¿Se cierra la vía democrática para los islamistas tras el golpe en Egipto? Disponible en: http://www.bbc.co.uk/mundo/noticias/2013/07/130702 egipto medio oriente jrg.sht

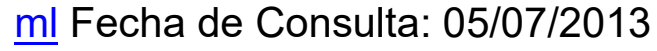

BBC MUNDO. D ¿Qué pasa hoy en los países de la Primavera Árabe? Disponible en:

http://www.bbc.co.uk/mundo/noticias/2013/02/130208 primavera arabe tunez dp.s html Fecha de consulta: 08/12/2013.

CAPELLA, Juan Ramón. Fruta Prohibida. Una aproximación histórico - teórica al estudio del derecho y del estado. Cuaderno marrón. Madrid: Trotta. 1997.

CASTELLS, Manuel. La Era de la Información. Economía Sociedad y Cultura. V.II. El poder de la identidad. Traducción: Carmen Martínez Gimeno. 7 Ed. México: Siglo XXI. 2008.

CASTELLS. Manuel. Comunicación y Poder. Traducción: Maria Hernandez Diaz. Alianza Editorial. Madrid. 2011.

CASTELLS, Manuel. Redes de indignación y esperanza. Trad. Maria Hernandez Díaz. Madrid: Alianza, 2012.

COMPARATO, F. K. A afirmação histórica dos direitos humanos. $5 .^{a}$ ed. Sao Paulo: Saraiva, 2007

CHILE. Instituto Nacional de Derechos Humanos. Reporte Información Constatada por el INDH al 15-01-2020 a las 16:00 hrs. Disponible en: https://www.indh.cl/bb/wp-content/uploads/2020/01/Reporte-15-enero-2020.pdf Fecha de consulta: 19/04/2020

DAHL, Robert. La democracia y sus críticos. Traducción: Leandro Wolfson. Barcelona: Paidos. 2000.

GROSSI, P. Europa y el Derecho. Giuliani L. (trad.) Barcelona: Crítica, 2008. 
HABERMAS, Jürgen. Direito e Democracia. Entre facticidade e validade. Volume. II. Tradução: Flávio Beno Siebeneichler. Rio de Janeiro: Tempo Brasileiro. 1997

HABERMAS, Jürgen. La constelación posnacional: ensayos políticos. Barcelona: Paidós. 2000.

MADISON, James, et. al. The Federalist Papers. No 10. Disponible en: http://www.foundingfathers.info/federalistpapers/fedindex.htm Fecha de Consulta: $10 / 05 / 2020$

MILL, John Stuart. Consideraciones sobre el gobierno representativo. Traducción, prologo y notas de Carlos Mellizo. Madrid: Alianza Editorial. 2001.

SANTOS, Boaventura de Sousa. Refundación del Estado en América Latina.

Perspectivas desde una epistemología del Sur. La Paz: Plural. 2010.

SCHUMPETER, Joseph. Capitalismo, socialismo y democracia. Traducción: José Díaz García. Madrid: Aguilar. 1968.

STIGLITZ, Joseph E. El precio de la desigualdad. El 1\% de la población tiene lo que el 99\% necesita. Bogotá: Taurus. 2012.

RINCON CORDOBA, Jorge Iván. Las generaciones de los derechos fundamentales y la acción de la Administración Pública. Bogotá: Universidad Externado. $2^{\mathrm{a}}$ Ed. 2004,

RIPERT, G. Aspectos jurídicos do capitalismo moderno. AZEVEDO, G. (trad.), Rio de Janeiro: Freitas Bastos, 1947

RODRÍGUEZ PEÑARANDA. María Luisa. Minorías, acción pública de inconstitucionalidad y democracia deliberativa. Bogotá: Universidad Externado de Colombia. 2005.

SIEYĖS, Joseph Emmanuel. ¿Qué es el tercer Estado? Precedido de «Ensayo sobre los privilegios». Introducción, traducción y notas de Marta Lorente Sarieña y Lidia Vázquez Jiménez. Madrid: Alianza Editorial. 2008.

TOCQUEVILLE, Alexis de. A democracia na América. Tradução de Neil Ribeiro da Silva. 2. ed. Belo Horizonte: Itatiaia; São Paulo: Edusp, 1987.

UPRIMMY, Rodrigo. Las transformaciones constitucionales recientes de América Latina: tendencias y desafíos. In: RODRIGO GARAVITO, Cesar. (coord.) EI derecho en América Latina. Un mapa para el pensamiento jurídico del siglo XXI. Buenos Aires: Siglo veintiuno. 2011.

VALENCIA TELLO, Diana Carolina; DINIZ LIMA, Edilson Vitorelli. A administração pública nas sociedades da informação e do conhecimento. In: Revista de Direito Administrativo. Vol. 262. Fundação Getúlio Vargas. 2013. 
VALENCIA-TELLO, Diana Carolina. EI Estado en la era de la globalización y las nuevas tecnologías. Bogotá: Ibañez, 2015.

WEBER, M. Economía y sociedad: teoría de la organización social. México: Fondo de Cultura Económica. 1963. v. 4.

Recebido em 15/05/2020

Aprovado em 13/08/2020

Received in 05/15/2020

Approved in 08/13/2020 